\title{
Energy Efficiency and Fuel Economy Analysis of a Series Hybrid Electric Bus in Different Chinese City Driving Cycles
}

\author{
Xiaogang $\mathrm{Wu}^{1}$, Jiuyu $\mathrm{Du}^{2}$ and $\mathrm{Chen} \mathrm{Hu}^{1}$ \\ ${ }^{1}$ Harbin University of Science and Technology, Harbin, China, 150080 \\ ${ }^{2}$ Tsinghua University, Beijing, China, 100084 \\ xgwu@hrbust.edu.cn
}

\begin{abstract}
Based on analysis of the configuration and powertrain parameters of the series hybrid electric bus typically operating in certain Chinese city, this paper establishes simulation model of the series hybrid powertrain. The energy efficiency and fuel economy of the series hybrid electric bus are analyzed by energy flow method in the driving cycles of Chinese typical city, Zhuzhou city in Hunan province of China, and Hefei city in Anhui province of China. Simulation results show that, APU parts selection, braking system configuration and control of the series hybrid electric bus can be optimized. The fuel-saving ratios reach nearly $20 \%$ in all driving cycles.
\end{abstract}

Keywords: Series Hybrid Electric Powertrain; Driving Cycle; Energy Efficiency; Fuel Economy; Analysis

\section{Introduction}

The series hybrid powertrain configuration has a large proportion of the new hybrid electric bus. Although series hybrid powertrain parts (generator, battery and drive motor) increase the bus mass, this configuration influences little on the power performance for the bus mass is already large [1-2]. Series hybrid powertrain configuration can effectively recover braking energy for brake is frequent in city driving cycle.

Literature [3] put forward a control strategy of series hybrid electric vehicle based on the minimum fuel consumption. Literature [4] used energy management strategy of power follow and super-capacitor to optimize the dynamic performance of a four-wheel drive series hybrid electric vehicle. Literature [5] texted a mini-series hybrid electric vehicle with super-capacitor in changing driving cycles. Literature [6-7] put forward and verified an optimal algorithm for the torque and speed of engine-generator for the series hybrid electric vehicle. Literature [8] used a strategy combining the equal minimum fuel consumption and cost MAP to increase the system energy efficiency of the series hybrid electric vehicle. Literature [9] used stochastic Markov model in the optimization of the powertrain model selection of the series hybrid electric vehicle. Literature [10] selected the series hybrid electric vehicle as study object and fuel economy as control object, established an energy management strategy based on logic threshold and fuzzy algorithm.

As is shown above, now the studies of the series hybrid electric vehicle mostly focus on optimizing the algorithm of model selection and energy management strategy. This paper uses the typically operating series hybrid electric bus in certain Chinese city, establishes hybrid electric system model, and analyzes the energy efficiency and fuel economy by energy flow method in the city driving cycles of Chinese typical city, Zhuzhou city and Hefei city. 
The energy efficiency optimization and fuel saving effect of the series hybrid electric bus is summarized in Chinese city driving cycle.

\section{Configuration Analysis of Series Hybrid Powertrain}

The configuration of the series hybrid electric vehicle is shown in Figure 1. Engine drives the generator to generate power and power is directly transferred to energy shortage unit or drive motor. Drive motor works in electric mode to drive the vehicle or in generating model to transfer mechanical energy to electric energy. The energy of the series hybrid electric vehicle is distributed by the vehicle controller. Vehicle controller distributes the energy between Auxiliary Power Unit (APU) and energy shortage unit according to the power demand of driver and parts condition. APU consists of diesel engine, electric excitation generator and three-phase uncontrollable rectifier, energy shortage unit uses super-capacitor, as is shown in Figure 2. APU output connects energy shortage unit and load.

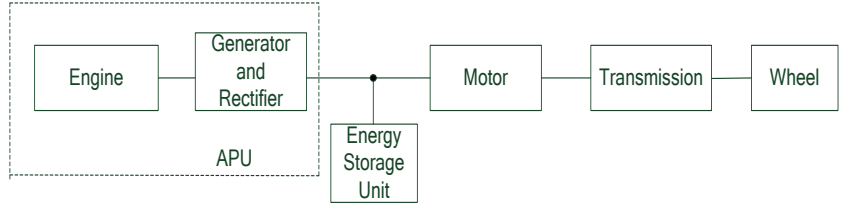

Figure 1. Series Hybrid Electric Vehicle Configuration

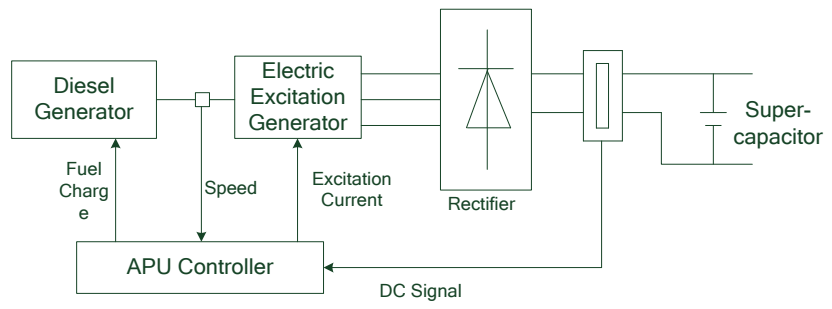

Figure 2. APU Configuration

\section{Modeling of Series Hybrid Powertrain}

In literature [11], the modeling method of series hybrid electric bus has been introduced. Based on the method, this paper establishes the simulation model of series hybrid electric bus according to the actual data and part data from literature [12-13]. As is shown in Figure 3, the simulation model consists of APU model, energy shortage unit model, traction motor model, transmission model and vehicle dynamics model.

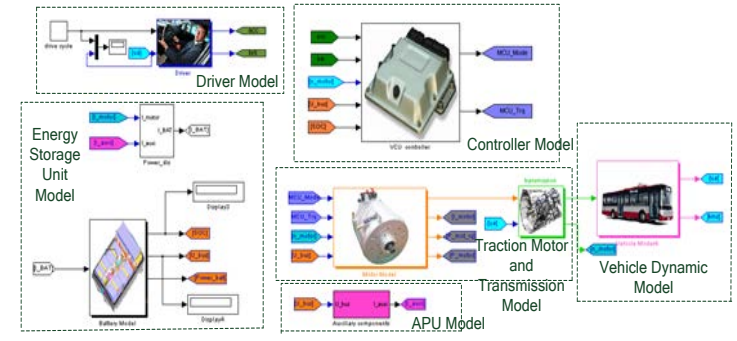

Figure 3. Simulation Model of Series Hybrid Electric Bus 
In the series hybrid system, engine, generator, rectifier-bridge and traction motor are highly complex. So this paper takes bench test and obtains MAP according to the results. The simulation model is established according to the MAP. The benefit of this way is that: using the MAP instead of complex mathematical description can reduce the difficulty of modeling and increase the reliability of the model. In simulation model, the vehicle distributes the proportion of brake by traction motor and the method is the same with the series hybrid bus operating in typical Chinese city.

\subsection{APU Simulation Model}

APU of the series hybrid powertrain consists of diesel engine, generator and rectifier. Followings are main formulas:

$$
\begin{gathered}
n_{\text {eng }}=n_{\mathrm{r}} \frac{1}{\tau_{\mathrm{e}} S+1} \\
T_{\text {eng }}=f_{1}\left(\alpha, n_{\text {eng }}\right) \\
C_{\text {eng }}=f_{2}\left(n_{\text {eng }}, T_{\text {eng }}\right) \\
\eta_{\mathrm{g}, \mathrm{r}}=f_{3}\left(n_{\mathrm{eng}}, \lambda\right) \eta_{\mathrm{r}}
\end{gathered}
$$

Where, $n_{\text {eng }}$ is diesel engine speed, unit is $\mathrm{r} / \mathrm{min} . n_{r}$ is diesel engine objective speed, unit is $\mathrm{r} / \mathrm{min} . \tau_{e}$ is time constant, $T_{\text {eng }}$ is diesel engine torque, unit is $\mathrm{N} \cdot \mathrm{m} . f_{1}$ is MAP of diesel engine accelerator performance data, $f_{2}$ is MAP of diesel fuel consumption performance data, $f_{3}$ is MAP of the generator efficiency data, $\alpha$ is accelerator signal, unit is $\%$. $\lambda$ is generator load rate, unit is $\% . \eta_{r}$ is the efficiency of rectifier bridge, unit is $\% . C_{e n g}$ is engine instantaneous fuel consumption, unit is $\mathrm{g} / \mathrm{kW} \cdot \mathrm{h}$. $\eta_{g . r}$ is the efficiency of generator and rectifier-bridge, unit is $\%$.

\subsection{Traction Motor Model}

Traction motor model consists of the MAP of the steady efficiency performance of traction motor bench test and one order inertial link. Followings are the main formulas:

$$
\begin{gathered}
\eta_{\mathrm{m}}=f_{\mathrm{m} 1}\left(n_{\mathrm{m}}, T_{\mathrm{m}}\right) \\
T_{\mathrm{m}}=\min \left(T_{\mathrm{r}}, T_{\max }\right) \frac{1}{\tau_{\mathrm{m}} S+1} \\
T_{\max }=f_{\mathrm{m} 2}\left(n_{\mathrm{m}}\right)
\end{gathered}
$$

Where, $\eta_{m}$ is the efficiency of traction motor, unit is $\%$. $f_{m 1}$ is the MAP of the efficiency of traction motor. $T_{m}, T_{r}, T_{\max }$ is traction motor output torque, objective torque and the maximal torque, unit is $\mathrm{N} \cdot \mathrm{m}, \tau_{m}$ is time constant, $f_{m 2}$ is the MAP of the maximum output torque of traction motor, $n_{m}$ is traction motor speed, unit is $\mathrm{r} / \mathrm{min}$.

\subsection{Energy Shortage Unit Model}

In the modeling of the super-capacitor, this paper references literature [14]. The following formulas can be obtained. 


$$
\left\{\begin{array}{l}
V_{C}=\frac{-V_{\mathrm{C}}}{C_{\mathrm{U}} \times R_{\mathrm{P}}}+\frac{i_{\mathrm{L}}}{C_{\mathrm{U}}} \\
V_{\mathrm{L}}=V_{\mathrm{C}}-E S R \times \dot{i}_{\mathrm{L}}
\end{array}\right.
$$

Where, $i_{L}$ is input current, unit is A. $V_{L}$ is output voltage, unit is V. ESR is equivalent resistance, unit is $\Omega$. $C_{u}$ is the volume of the super-capacitor, unit is F.

\subsection{Transmission Model}

The transmission system model mainly references literature [15] and the actual data of the driving series hybrid bus and the gearbox has only one shift. The speed ratio is 2.46 according to the matching calculation of the dynamic system and the actual driving data. The transmission system model can be described as the followings:

$$
\begin{gathered}
n_{\text {motor }}=2.46 i_{0} i_{\mathrm{g}} u_{\mathrm{a}} / r \\
T_{\text {motor }}=\frac{T_{\mathrm{a}}}{i_{0} i_{\mathrm{g}} \eta_{\mathrm{T}}}
\end{gathered}
$$

Where, $n_{\text {motor }}$ is the traction motor speed, unit is $\mathrm{r} / \mathrm{min}$. $i_{0}$ is the main speed ratio of the main reducer. $i_{g}$ is the main gearbox reduction ratio. $u_{a}$ is the speed, unit is $\mathrm{km} / \mathrm{h} . r$ is the radius of the wheel, unit is $\mathrm{m}$. $T_{\text {motor }}$ is the traction motor output torque, unit is $\mathrm{N} \cdot \mathrm{m} . T_{a}$ is the full driving torque on wheel, unit is $\mathrm{N} \cdot \mathrm{m} . \eta_{T}$ is the system full efficiency, unit is $\%$.

\subsection{Vehicle Dynamics Model}

In vehicle dynamics model, the absolute air speed is zero, the vehicle is driving on the well cement. The traction motor needs to overcome the driving resistances $\left(F_{t}\right)$ of rolling resistance $\left(F_{f}\right)$, air resistance $\left(F_{w}\right)$, slope resistance $\left(F_{i}\right)$ and acceleration resistance $\left(F_{j}\right)$.

$$
\begin{gathered}
F_{\mathrm{t}}=F_{\mathrm{f}}+F_{\mathrm{w}}+F_{\mathrm{i}}+F_{\mathrm{j}} \\
F_{\mathrm{f}}=f m g \cos (\arctan i) \\
F_{\mathrm{w}}=\frac{1}{2} C_{\mathrm{d}} A \rho u_{\mathrm{a}}^{2} \\
F_{\mathrm{i}}=m g \sin (\arctan i) \\
F_{\mathrm{j}}=0.28 \delta m \frac{d u_{\mathrm{a}}}{d t} \\
F_{\mathrm{t}}=3.6 \eta_{\mathrm{T}} P_{\text {motor }} / u_{\mathrm{a}}
\end{gathered}
$$

Where, $f$ is rolling resistance coefficient. $m$ is the bus mass, unit is $\mathrm{kg} . g$ is gravitational acceleration, unit is $\mathrm{m} / \mathrm{s}^{2} . i$ is road gradient, unit is \%. $C_{d}$ is air resistance coefficient. $A$ is windward area, unit is $\mathrm{m}^{2} . \rho$ is air density, unit is $\mathrm{kg} / \mathrm{m}^{3} . u_{a}$ is vehicle speed, unit is $\mathrm{km} / \mathrm{h} . \delta$ is correction coefficient of rotating mass. $\eta_{T}$ is the system full efficiency, unit is $\%$. $P_{\text {motor }}$ is traction motor output power, unit is W. 


\section{Energy Management Strategy of Series Hybrid Electric Bus}

Energy management strategy has the potential of increasing the fuel economy of the series hybrid electric bus. Although the common algorithms are fuzzy logic algorithm based on complex rule, global optimization algorithm based on set driving cycle and instantaneous optimization algorithm based on minimum fuel consumption, this paper mainly focuses on the influence of Chinese city driving cycle on the fuel consumption of the series hybrid electric bus, so in simulation, the algorithm is power follow algorithm based on rules.

Energy distribution strategy is based on SOC of energy shortage unit by estimating the stable output power. Power of energy shortage unit is defined as positive if energy shortage unit transfers power to bus. Power of energy shortage unit is defined as negative if energy shortage unit get power from bus.

Power of APU, energy shortage unit and drive motor fit formula 17 that is balance relationship of power energy. After the objective power of energy shortage unit is defined, the objective power of APU is defined.

$$
P_{\text {APU }}=P_{m o t}-P_{b a t}+P_{a}
$$

In formula $17, P_{A P U}$ is the APU output power, unit is $\mathrm{kW} . P_{m o t}$ is the traction motor controller inlet power, unit is $\mathrm{kW}$. $P_{b a t}$ is the energy storage unit power, unit is $\mathrm{kW} . P_{a}$ is the auxiliaries consumption power, auxiliaries include air condition, battery heat management system, interior heating system, lighting and control system, steering and braking consumption [16], unit is kW.

Energy distribution strategy is a kind of static distribution strategy, if APU can't fit the objective power, $P_{A P U}$, in dynamic process; battery doesn't work in the distribution result of the steady distribution curve but in the energy balance relationship in formula 17 to fit the power demand of the drive motor. Energy management algorithm is realized by controlling the pedal and excitation of APU.

\section{Simulation Results and Analysis}

To analyze the fuel saving effect of the series hybrid electric bus in Chinese city driving cycle, this paper uses driving cycles of Chinese typical city, Zhuzhou city and Hefei city to analyze the energy efficiency and fuel saving effect in different driving cycles. The driving cycles in simulation are shown in Figure 4.

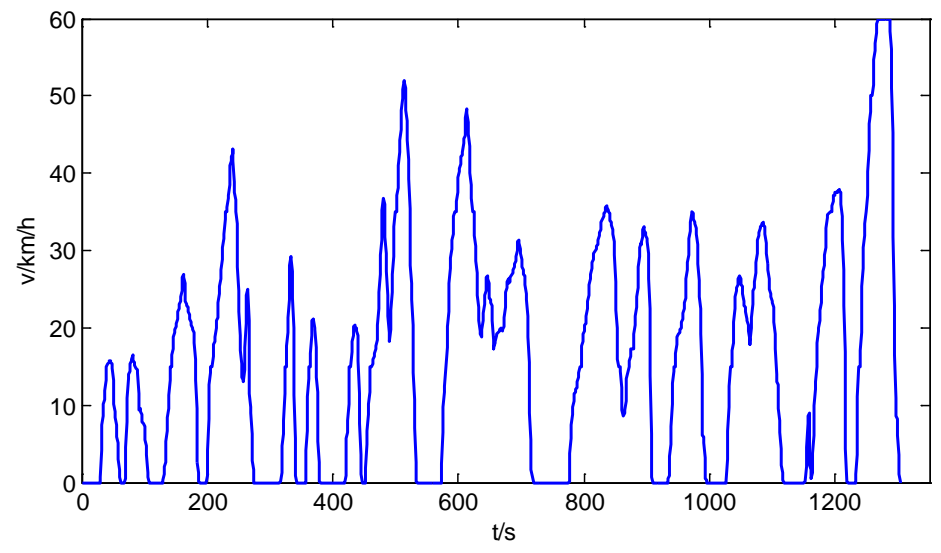

(a) Chinese typical city driving cycle 


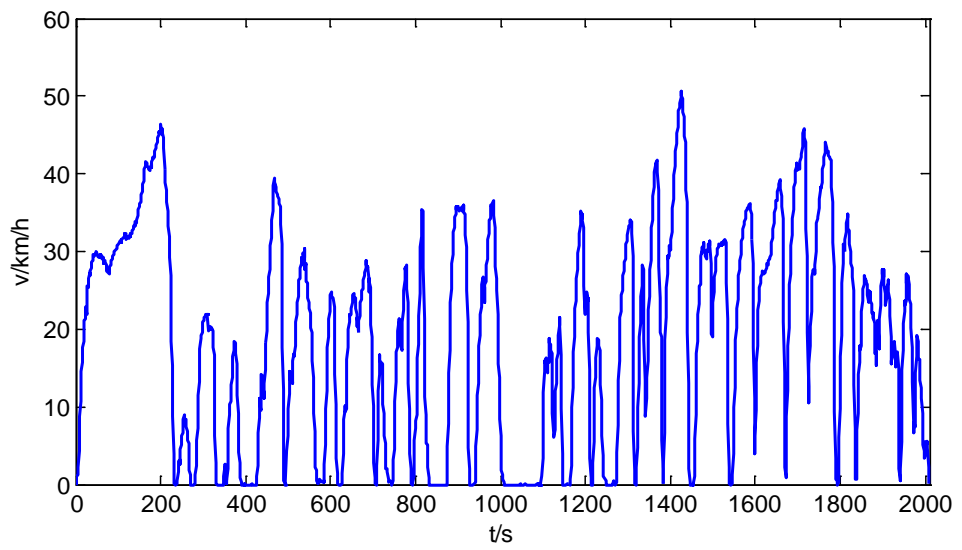

(b) Zhuzhou city driving cycle

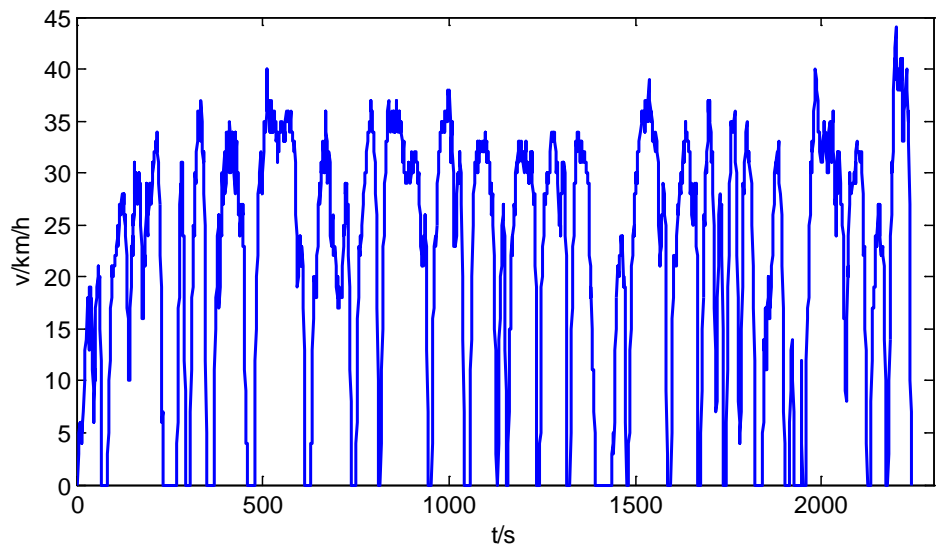

(c) Hefei city driving cycle

Figure 4. Driving Cycles in Simulation

Table 1. Characteristic Values of Driving Cycles in Simulation

\begin{tabular}{|c|c|c|c|}
\hline Performance statistics & Chinese typical city & Zhuzhou city & Hefei city \\
\hline Cycle time $/ \mathrm{s}$ & 1304 & 2010 & 2242 \\
\hline Trip mileage $/ \mathrm{km}$ & 5.83 & 10.56 & 13.37 \\
\hline Maximum speed $/ \mathrm{km} / \mathrm{h}$ & 59.98 & 50.55 & 44 \\
\hline Average speed $/ \mathrm{km} / \mathrm{h}$ & 16.1 & 18.91 & 21.48 \\
\hline Maximum acceleration $/ \mathrm{m} / \mathrm{s}^{-2}$ & 1.25 & 1.26 & 1.944 \\
\hline Maximum deceleration $/ \mathrm{m} / \mathrm{s}^{-2}$ & -2.47 & -2.75 & -3.056 \\
\hline Average acceleration $/ \mathrm{m} / \mathrm{s}^{-2}$ & 0.31 & 0.27 & 0.52 \\
\hline Average deceleration $/ \mathrm{m} / \mathrm{s}^{-2}$ & -0.43 & -0.37 & -0.59 \\
\hline Idle ratio/\% & 28.75 & 12.63 & 15.83 \\
\hline
\end{tabular}

Parameters of the model in simulation are shown in Table 2.

To compare the influence of different driving cycles on economy of the series hybrid electric bus, the energy of air-condition and power steering is provided by engine, average power is $4 \mathrm{~kW}$. Initial and stop value is set same value in simulation. 
Table 2. Parameters of the Model in Simulation

\begin{tabular}{|c|c|}
\hline Length, width and height(mm) & $11980 \times 2550 \times 3180$ \\
\hline Mass(kg) & 12900 \\
\hline Engine rated power(kW) & 118 \\
\hline Engine rated power speed(r/min) & 2500 \\
\hline Engine maximum torque $(\mathrm{N} \cdot \mathrm{m})$ & 600 \\
\hline Engine maximum torque speed(r/min) & 1300 \\
\hline Generator maximum rotary speed(r/min) & 1500 \\
\hline DC output voltage with full-wave rectification(V) & $360 \sim 460$ \\
\hline Energy storage unit & Super-capacitor11.7F \\
\hline Traction motor type & JD147A \\
\hline Traction motor maximum rotary speed(r/min) & 4500 \\
\hline Traction motor highest/rated power(kW) & $160 / 80$ \\
\hline Traction motor maximum torque & $\geq 1300$ N.m \\
\hline Transmission main reduction ratio & 6.333 \\
\hline
\end{tabular}

\subsection{Energy Efficiency Analysis of Chinese Typical City Driving Cycle}

The model of series hybrid electric bus is simulated in Chinese typical city driving cycle, speed tracking curve, SOC of super-capacitor curve, bus voltage curve, in/out put current of super-capacitor curve, output current of APU curve, input current of drive motor curve are shown in Figure 5.

As is shown in Figure 5, in Chinese typical driving cycle, as the final acceleration of the vehicle reaches $59.98 \mathrm{~km} / \mathrm{h}$, the output current of APU reaches the maximum value set by energy management strategy. To supplement the power needed in vehicle operation, output current of super-capacitor also reaches near 400A. Bus voltage is decreased rapidly, SOC of super-capacitor decreases near $40 \%$.

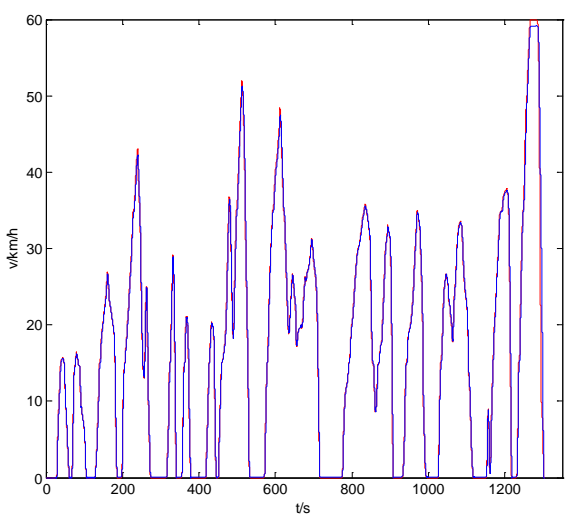

(a) Speed tracking cuvre

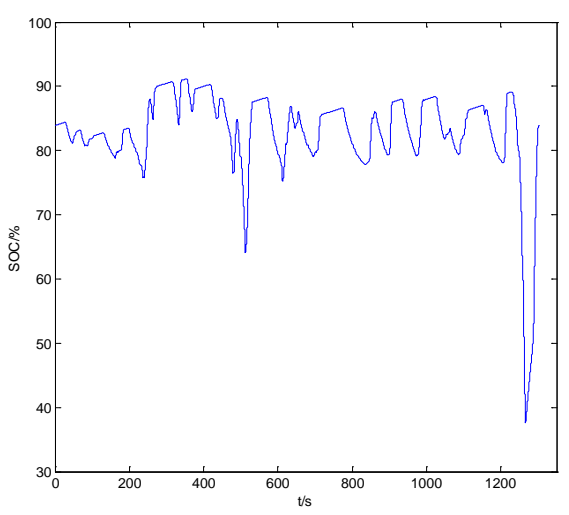

(b) SOC of super-capacitor curve 


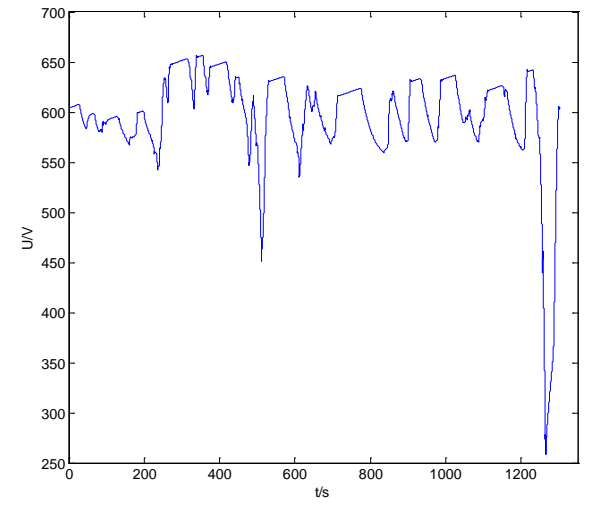

(c) Bus voltage curve

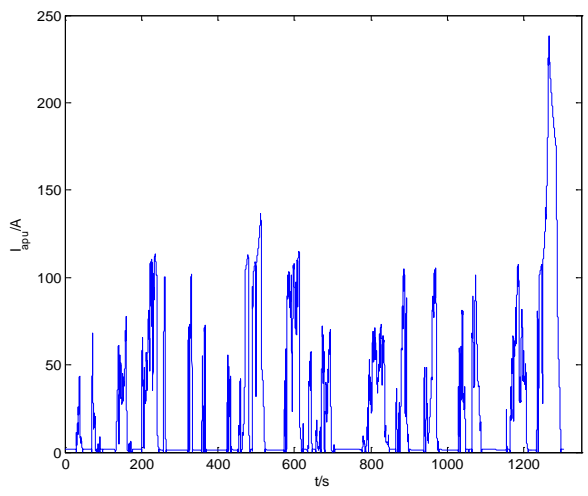

(e) Output current of APU curve

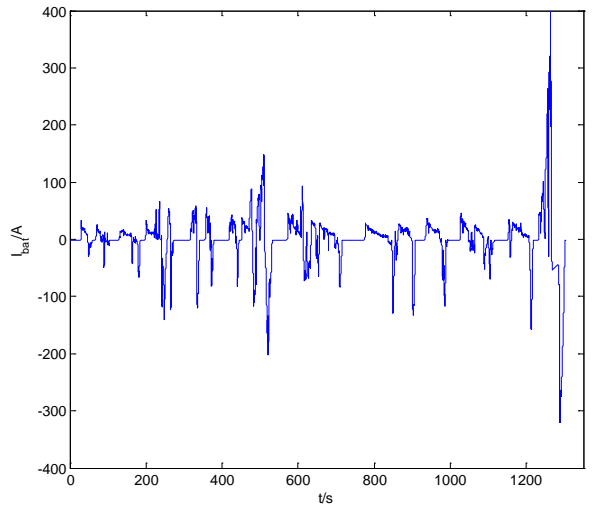

(d) Input current of super-capacitor

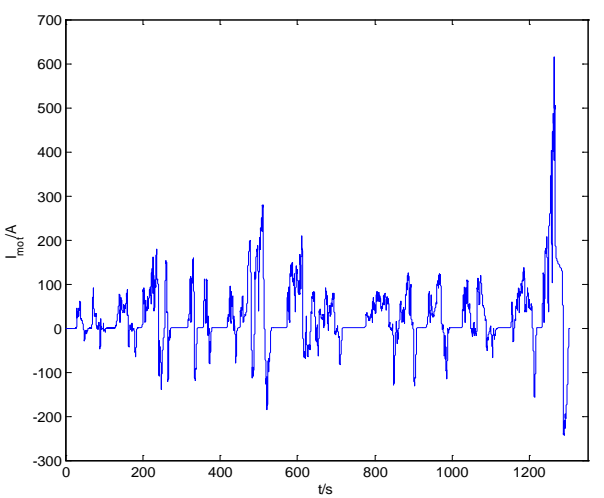

(f) Input current of drive motor curve

\section{Figure 5. Simulation Results in Chinese Typical City Driving Cycle}

Figure 6 is the series hybrid powertrain energy flow chart in Chinese typical city driving cycle. As is shown in Figure 6, if using output energy that drives the vehicle as the reference value, in Chinese typical city driving cycle, braking energy in theory can reaches $55.39 \%$. But actual recovery energy only reaches $34.147 \%$, so the configuration and control of the series hybrid electric bus some the optimization space. As using super-capacitor, the charge and discharge ratio of the energy shortage unit can reaches $97.04 \%$. The energy efficiency of generator and rectifier is low, only reaches $72.25 \%$, so the optimization space of the configuration selection is large. 


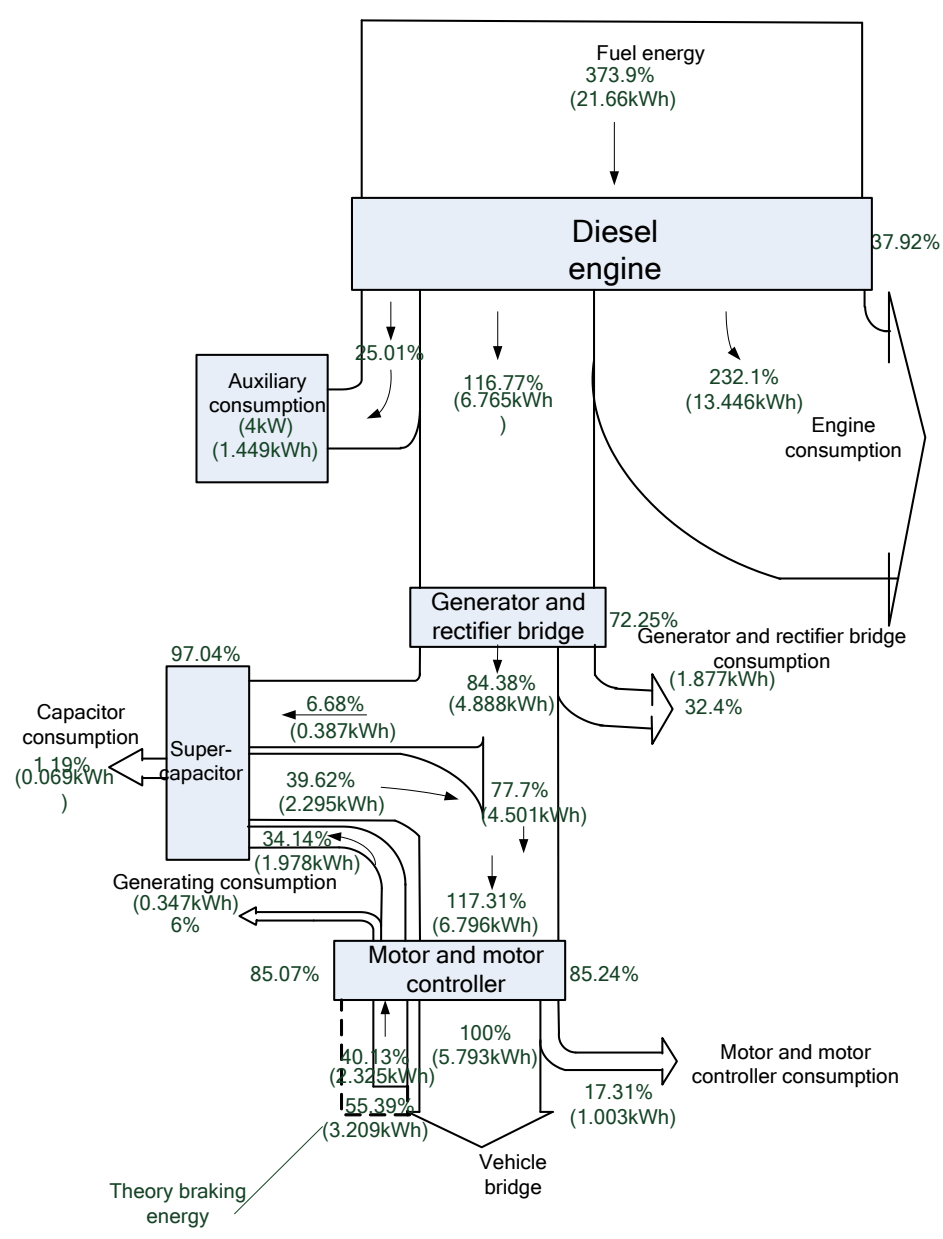

Figure 6. The Series Hybrid Powertrain Energy Flow Chart in Chinese Typical City Driving Cycle

\subsection{Energy Efficiency Analysis of Zhuzhou City Driving Cycle}

The model of series hybrid electric bus is simulated in Zhuzhou city driving cycle, speed tracking curve, SOC of super-capacitor curve, bus voltage curve, in/out put current of supercapacitor curve, output current of APU curve, input current of drive motor curve are shown in figure 7.

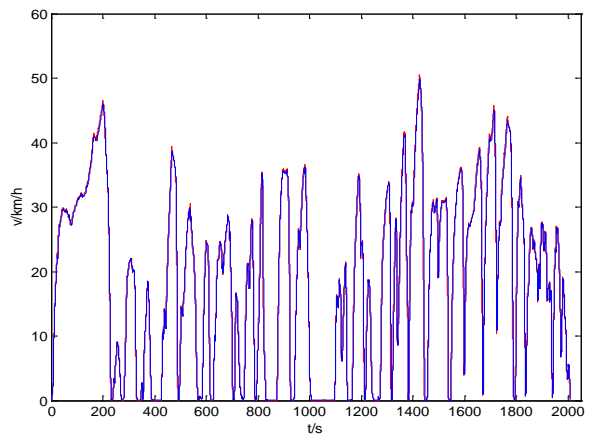

(a) Speed tracking cuvre

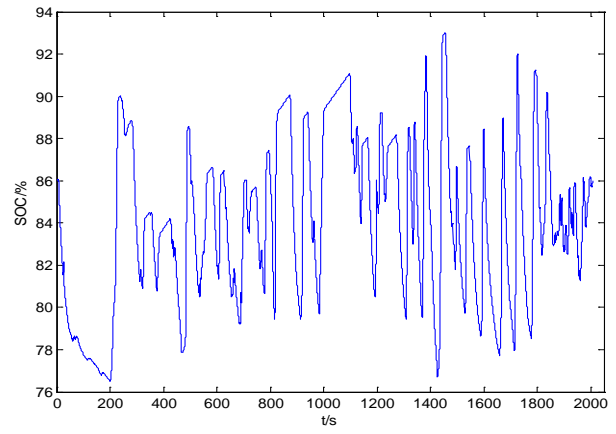

(b) SOC of super-capacitor curve 


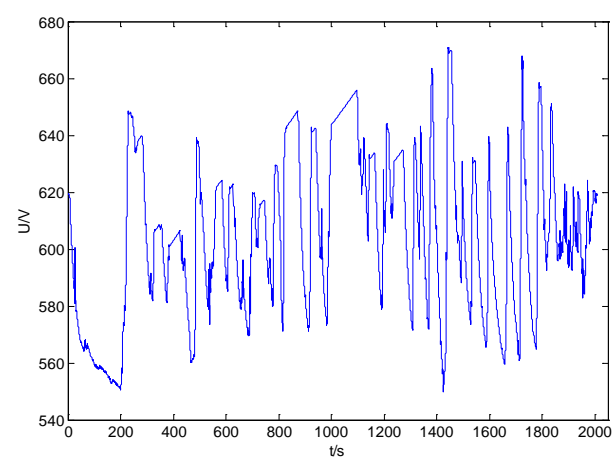

(c) Bus voltage curve

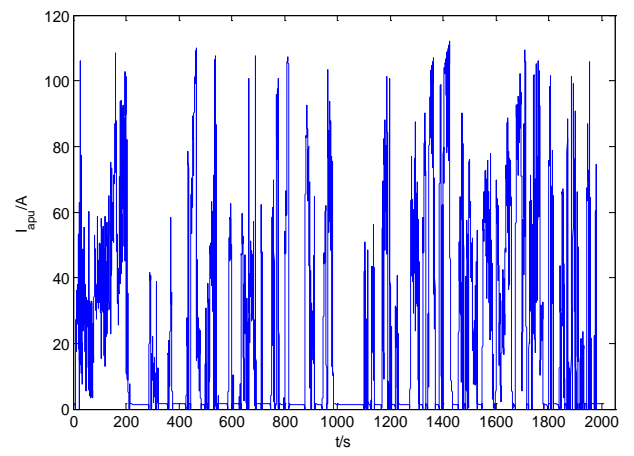

(e) Output current of APU curve

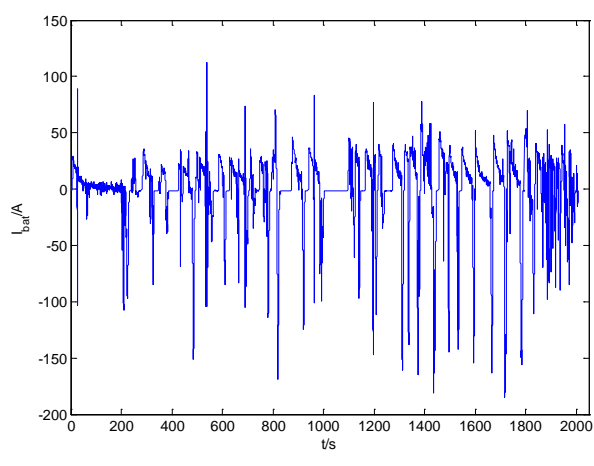

(d) Input current of super-capacitor

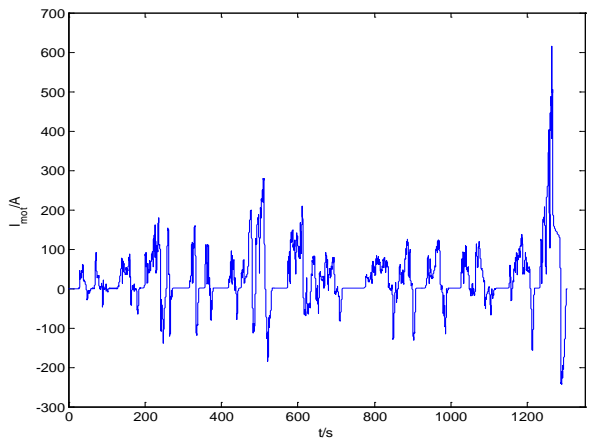

(f) Input current of drive motor curve

Figure 7. Simulation Results in Zhuzhou City Driving Cycle

As is shown in Figure 7, in Zhuzhou city driving cycle, as the maximum speed only reaches $50.55 \mathrm{~km} / \mathrm{h}$, the maximum output current of APU only reaches $115 \mathrm{~A}$; output current of super-capacitor reaches nearly 110A. Range of bus voltage is narrow, SOC of supercapacitor ranges from $76 \%$ to $93 \%$.

Figure 8 is the series hybrid powertrain energy flow chart in Zhuzhou city driving cycle. If using output energy that drives the vehicle as the reference value, in Zhuzhou city driving cycle, braking energy in theory can reaches $52.09 \%$. But actual recovery barking energy only reaches $32.88 \%$. As using super-capacitor, the charge and discharge ratio reaches $98.37 \%$. The energy efficiency of generator and rectifier only reaches $72.25 \%$. 


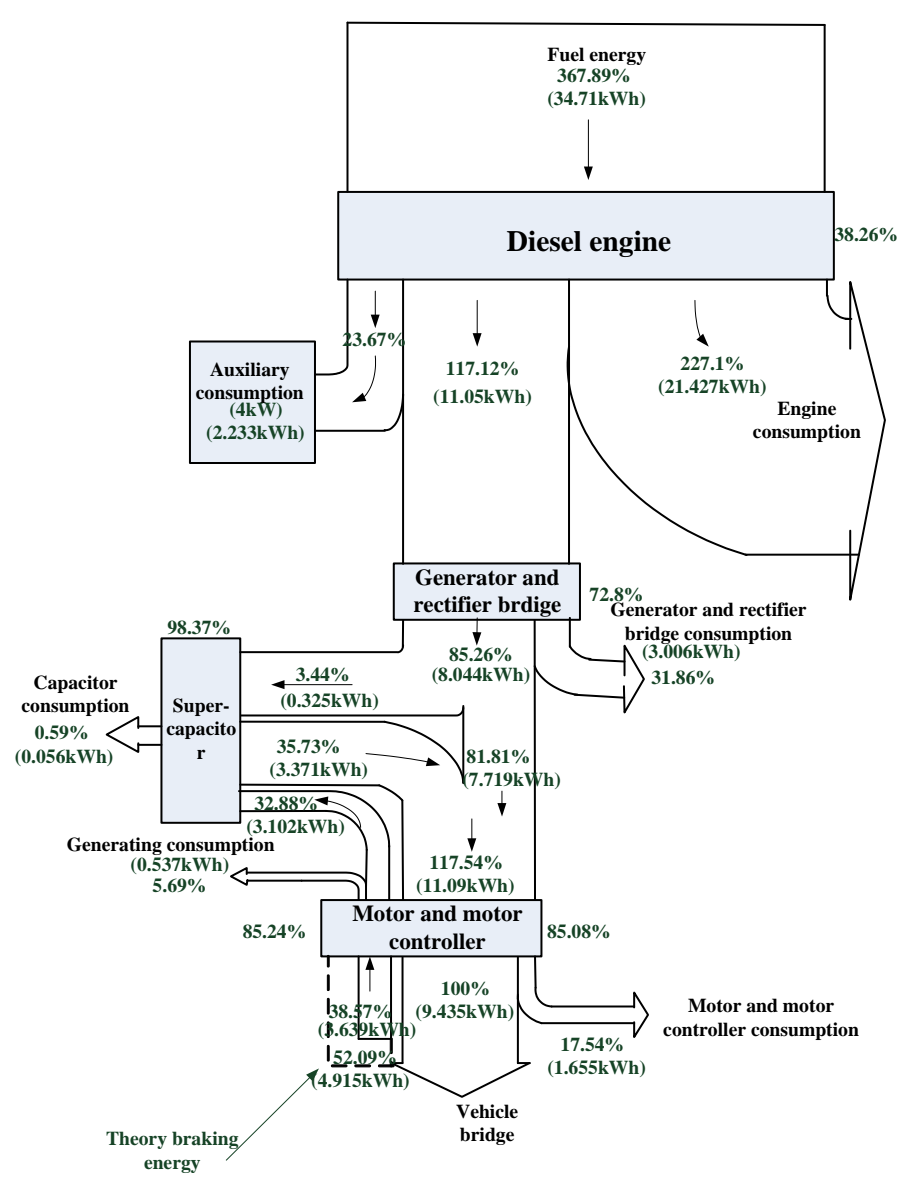

Figure 8. The Series Hybrid Powertrain Energy Flow Chart in Zhuzhou City Driving Cycle

\subsection{Energy Efficiency Analysis of Hefei City Driving Cycle}

The model of series hybrid electric bus is simulated in Hefei city driving cycle, speed tracking curve, SOC of super-capacitor curve, bus voltage curve, in/out put current of supercapacitor curve, output current of APU curve, input current of drive motor curve are shown in Figure 9.

As is shown in Figure 9, in Hefei city driving cycle, as the maximum speed is only $44 \mathrm{~km} / \mathrm{h}$, the maximum output current of APU only reaches 120A; output current of super-capacitor reaches nearly 150A. Range of bus voltage is narrow, SOC of super-capacitor ranges from $72 \%$ to $92 \%$. 


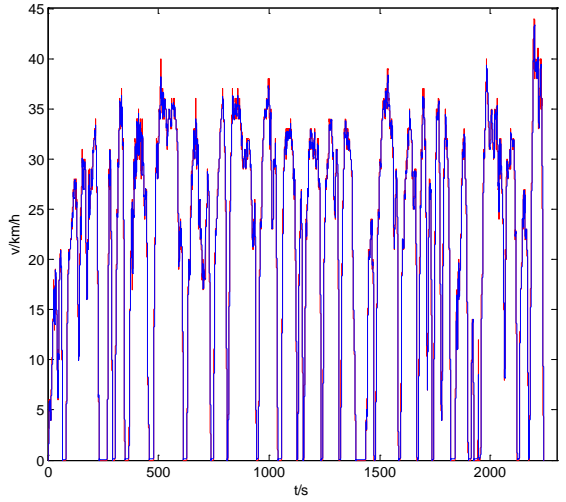

(a) Speed tracking curve

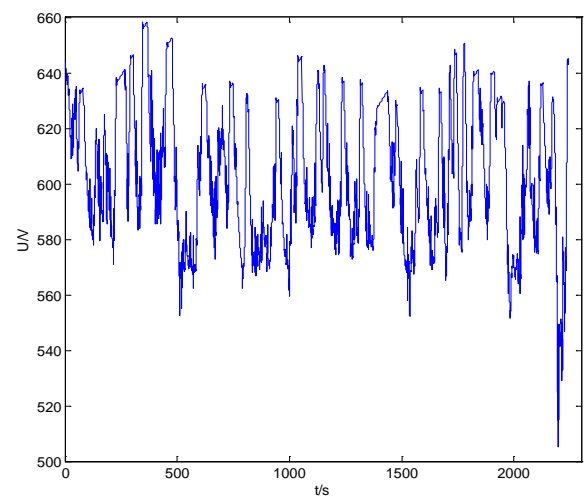

(c) Bus voltage curve

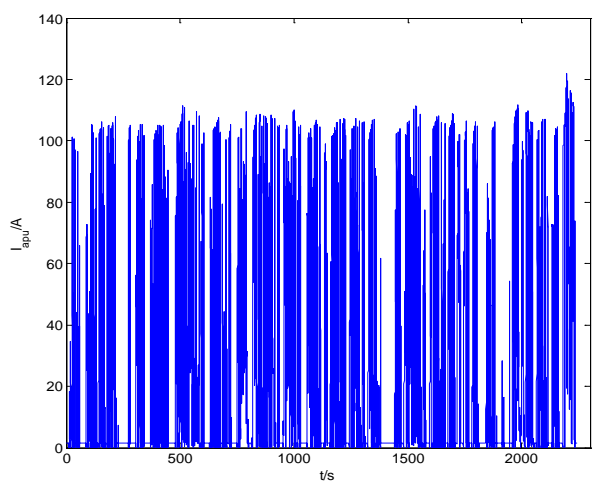

(e) Output current of APU curve

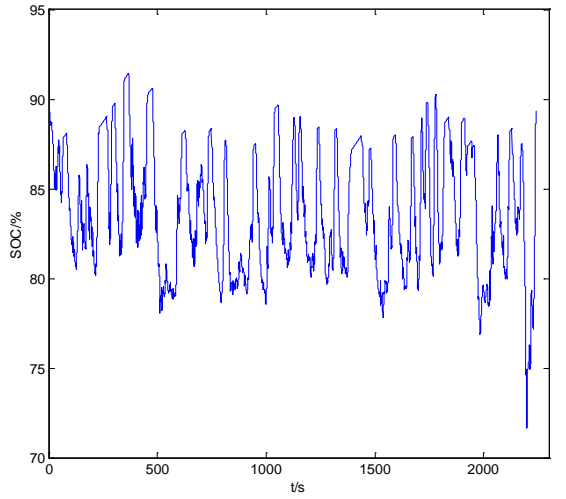

(b) SOC of super-capacitor curve

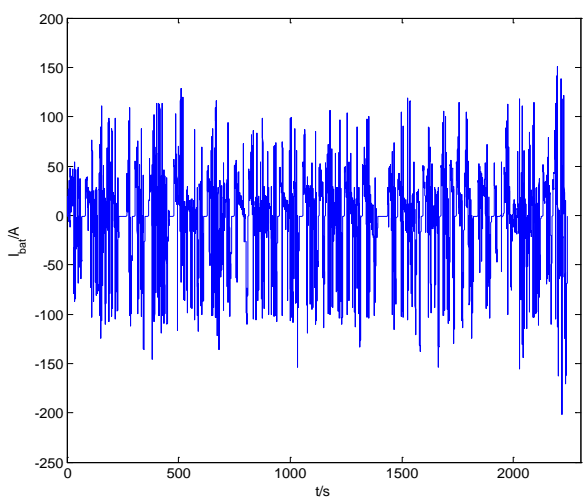

(d) Input current of super-capacitor

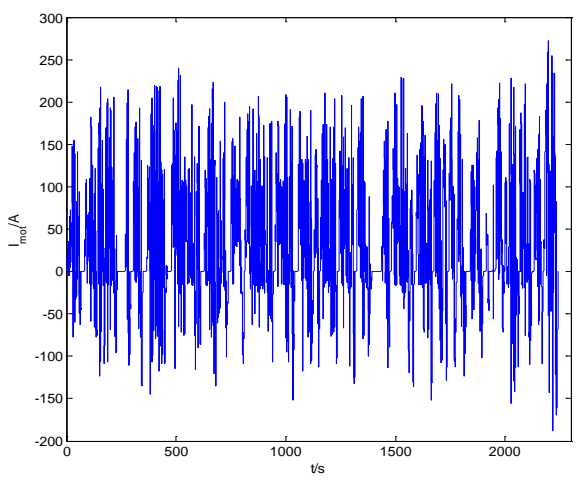

(f) Input current of drive motor curve

Figure 9. Simulation Results in Hefei City Driving Cycle

Figure 10 is the series hybrid powertrain energy flow chart in Hefei city driving cycle. If using output energy that drives the vehicle as the reference value, in Hefei city driving cycle, braking energy in theory can reaches 53.58\%. But actual recovery barking energy only reaches $33.79 \%$. As using super-capacitor, the charge and discharge ratio reaches $98.3 \%$. The energy efficiency of generator and rectifier only reaches $74.5 \%$. 


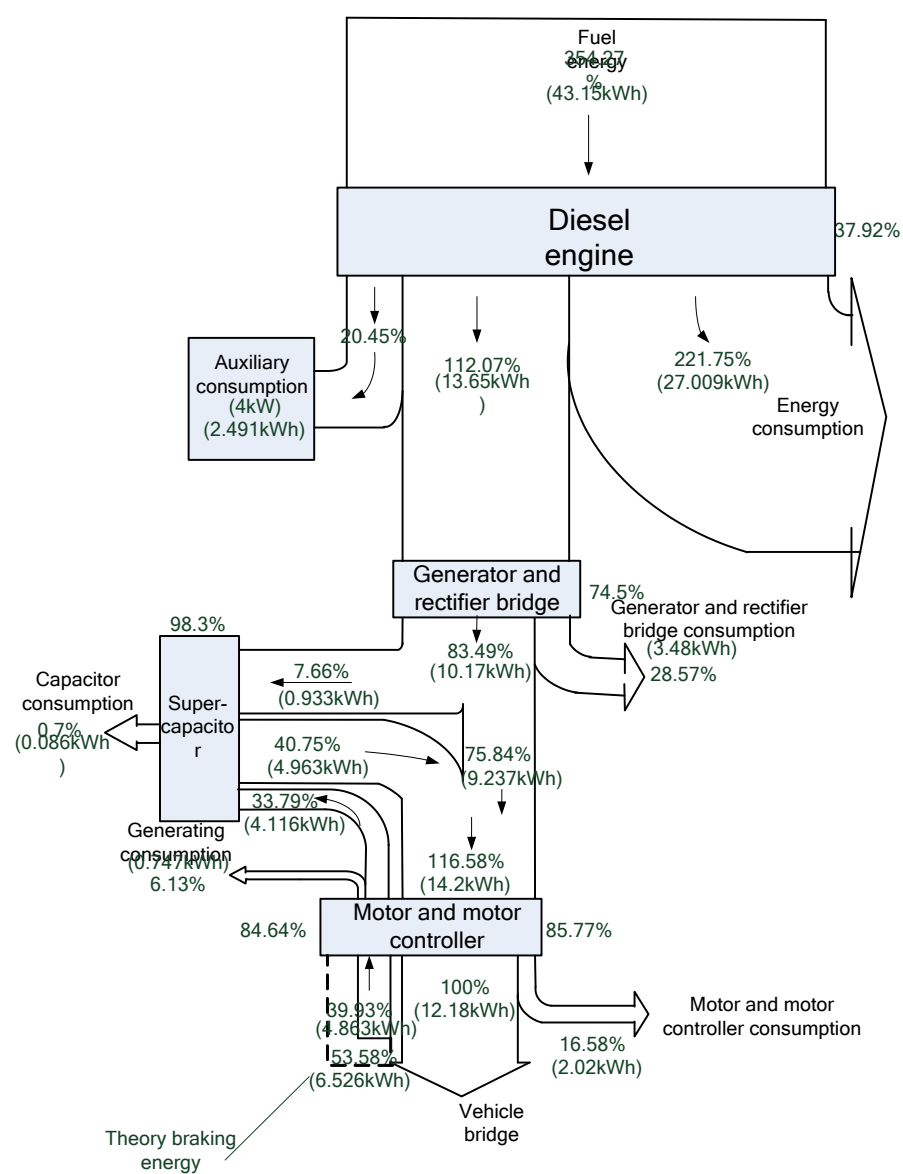

\section{Figure 10. The Series Hybrid Powertrain Energy Flow Chart in Hefei City Driving Cycle}

Table 3 is the economy comparison between series hybrid electric bus and conventional fuel bus in the three different city driving cycle.

Table 3. Economy Comparison between Series Hybrid Electric Bus and Conventional Fuel Bus

\begin{tabular}{|c|c|c|c|}
\hline & Chinese typical city & Zhuzhou city & Hefei city \\
\hline $\begin{array}{c}\text { Fuel consumption of conventional fuel bus } \\
\text { (L/100km) }\end{array}$ & 38.64 & 34.74 & 33.83 \\
\hline $\begin{array}{c}\text { Fuel consumption of series hybrid electric } \\
\text { bus(L/100km) }\end{array}$ & 31.21 & 27.73 & 27.21 \\
\hline Fuel saving ratio (\%) & 19.22 & 20.17 & 19.57 \\
\hline
\end{tabular}

As is shown in Table 3, all the fuel saving ratios of the series hybrid electric bus can reach above $19 \%$ in different Chinese city driving cycles. In Zhuzhou city driving cycle, the fuel saving ratio can reach $20.17 \%$. The result fits the experiment result of the typical city. 


\section{Conclusion}

Based on establishing the simulation model of a series hybrid electric bus operating in certain Chinese city, this paper uses Chinese typical city, Zhuzhou city in Hunan province of China and Hefei city in Anhui province of China as driving cycles in simulation, analyzes the energy efficiency and fuel economy of the series hybrid powertrain.

(1) As the energy shortage unit uses super-capacitor, all the charge and discharge efficiencies in the three different city driving cycles are above $97 \%$.

(2) All the braking energy in theory are above $50 \%$ of the vehicle drive energy in the three different driving cycles, but now the recovery braking energy of the series hybrid powertrain only reaches $32 \%-34 \%$. So the brake system can be optimized.

(3) Now the energy efficiency of the electrical excitation generator and rectifier of the typically operating series hybrid powertrain only reaches $72 \%-74 \%$, so optimization space of the parts selection is relatively large.

(4) All fuel saving ratios can reach above $19 \%$ in the three different Chinese city driving cycles. In Zhuzhou city driving cycle, the maximum fuel saving ratio can reach $20.17 \%$.

\section{Acknowledgements}

This work is supported by National Natural Science Foundation (NNSF) of China (Grant No.51105220), National Science and Technology Infrastructure Program(Grant No.2013BAG06B04), and the Postdoctoral research startup of Heilongjiang Province(Grant No.LBH-Q12068)

\section{References}

[1] T. Ciccarelli and R. Toossi, "Assessment of hybrid configuration and control strategies future metropolitan/urban transit bus”, Final Report of California State University Long Beach, (2002).

[2] C. Guijun, L. Languang, X. Huasheng, L. Jianqiu and O. Minggao, "Experimental study on fuel economy of diesel based series hybrid power train for city bus”, Chinese Internal Combustion Engine Engineering, , vol. 30, no. 1, (2009), pp. 1-6.

[3] S. Barsali, C. Miulli and A. Possenti, “A control strategy to minimize fuel consumption of series hybrid electric vehicles”, IEEE Transactions on Energy Conversion, vol. 19, no. 1, (2004), pp. 187-195.

[4] H. Yoo, S.-K. Sul, Y. Park and J. Jeong, "System integration and power-flow management for a series hybrid electric vehicle using supercapacitors and batteries”, IEEE Transactions on Industry Applications, vol. 44, no. 1, (2008), pp. 108-114.

[5] A. Lidozzi, L. Solero and A. Di Napoli, "Ultracapacitors equipped hybrid electric microcar”, IET Electric Power Applications, vol. 4, no. 8, (2010), pp. 618-628.

[6] C. E. Nino-Baron, A. Rehman Tariq, G. Zhu and E. G. Strangas, "Trajectory optimization for the enginegenerator operation of a series hybrid electric vehicle”, IEEE Transactions on Vehicular Technology, vol. 60, no. 6, (2011), pp. 2438-2447.

[7] Z. Xi and Y. Pingxi, "Sliding mode of powertrain for SHEV with a desired battery charging curve set", Automotive Engineering, vol. 33, no. 4, (2011), pp. 352-356.

[8] V. Sezer, M. Gokasan and S. Bogosyan, "A novel ECMS and combined cost MAP approach for highefficiency series hybrid electric vehicles”, IEEE Transactions on Vehicular Technology, vol. 60, no. 8, (2011), pp. 3557-3570.

[9] G. Souffran, L. Miegeville and P. Guerin, "Simulation of real-world vehicle missions using a stochastic markov model for optimal powertrain sizing”, IEEE Transactions on Vehicular Technology, vol. 61, no. 8, (2012), pp. 3454-3465.

[10] Z. Guangyao, C. Zeyu and D. Zhiyuan, "Energy management strategy for series hybrid electric vehicle”, Journal of Northeastern University(Natural Science), vol. 34, no. 4, (2013), pp. 583-587. 
[11] X. Huasheng, C. Guijun, L. Languang, O. Minggao and L. Jianqiu, "Simulation system of series hybrid powertrain for city bus and its applications”, Journal of System Simulation, vol. 22, no. 5, (2010), pp. 11341138.

[12] C. Guijun and O. Minggao, "Experimental investigation of the control system of a diesel-hybrid powertrain”, Journal of Tsinghua University (Science and Technology), vol. 49, no. 11, (2009), pp. 1843-1847.

[13] C. Guijun, Y. Fengjun and L. Xuefeng, "A study on the control of auxiliary power unit of series hybrid electric bus”, Automotive Engineering, vol. 29, no. 4, (2007), pp. 321-324.

[14] X. Rui, H. Hongwen and Z. Xiaowei, "Modeling of ultracapacitor based on experimental data”, Vehicle and Power Technology, vol. 4, (2010), pp. 25-28.

[15] H. Hua, Y. Fuyuan, Y. Yuping and O. Minggao, "Development of CNG-fueld series hybrid electric city bus”, Automotive Engineering, vol. 30, no. 3, (2008), pp. 202-205.

[16] J. Campbell, W. Watts and D. Kittelson, "Reduction of accessory overdrive and parasitic loading on a parallel electric hybrid city bus”, SAE 2012-01-1005. 
International Journal of Smart Home Vol.7, No.5 (2013) 